DOI: $10.2478 / \mathrm{v} .10169-011-0025-1$

\title{
FLEXIBL PAVEMENT ANALYSIS CONSIDERING TEMPERATURE PROFILE AND ANISOTROPY BEHAVIOR IN HOT MIX ASPHALT LAYER
}

\author{
JOONHO CHOI ${ }^{1}$, YOUNGGUK SEO ${ }^{2}$, SUNG-HEE KIM ${ }^{3}$, \\ SAMUEL BEADLES ${ }^{4}$
}

\begin{abstract}
A three Dimensional finite element model (FEM) incorporating the anisotropic properties and temperature profile of hot mix asphalt (HMA) pavement was developed to predict the structural responses of HMA pavement subject to heavy loads typically encountered in the field. In this study, ABAQUS was adopted to model the stress and strain relationships within the pavement structure. The results of the model were verified using data collected from the Korean Highway Corporation Test Road (KHCTR). The results demonstrated that both the base course and surface course layers follow the anisotropic behavior and the incorporation of the temperature profile throughout the pavement has a substantial effect on the pavement response predictions that impact pavement design. The results also showed that the anisotropy level of HMA and base material can be reduced to as low as $80 \%$ and $15 \%$ as a result of repeated loading, respectively.
\end{abstract}

Key words: Anisotropic Behavior, Finite Element Method, Aggregate Base, HMA

\section{INTRODUCTION}

Existing FEMs that model the behavior of layers in HMA pavement rely on simplifying assumptions about the variations of the properties within the pavement. Specifically, existing models assume linear and isotropic variations within the layers of the pavement and use the annual maximum or minimum pavement temperature to recommend a suitable asphalt binder performance grade. These assumptions are made in order to reduce the computational complexity involved in modeling the behavior of HMA pavement. A number of researchers, however, have shown that the pavement materials

\footnotetext{
${ }^{1}$ Postdoctoral Research Fellow, Georgia Institute of Technology, Phone: 404-421-5541, e-mail: joonho.choi@gmail.com

2 Pavement Research Group, Expressway \& Transportation Research Institute Korea Expressway Corporation, Phone: +82-031-371-3368, e-mail: seoyg89@hotmail.com

${ }^{3}$ (Corresponding Author) Assistant Professor, Civil and Construction Engineering, Southern Polytechnic State University, 1100 South Marietta Parkway, Marietta, GA 30060, Phone (678) 915-5491, e-mail: skim4@spsu.edu

${ }^{4}$ Professor, Civil and Construction Engineering, Southern Polytechnic State University, 1100 South Marietta Parkway, Marietta, GA 30060, Phone (678) 915-7294, e-mail: sbeadles@ spsu.edu
} 
exhibit nonlinear, anisotropic behavior (Кıм et al. [3], KIм et al. [4], Kıм et al. [5], TutUMLUER et al. [9]). Researchers also mentioned that the structural or load-carrying capacity of the pavement varies with temperature for HMA layer and it is necessary to predict the temperature distribution within the HMA layers to accurately determine in situ strength characteristics of flexible pavement (DIEFENDERFER et al. [1]).

This paper deals with the predictions of the pavement critical responses using three dimensional FEM analysis technique. The FEM developed using ABAQUS in this study incorporates the anisotropic properties of the HMA and base layers with temperature profile variations through the HMA layer. The approach was also validated by comparing measured pavement responses with the predictions of the three dimensional finite element analysis results.

\section{Anisotropic BehaVIor of GRANUlAR MATERIALS}

Inherent anisotropy in granular materials exists even before the pavement is subjected to traffic due to the effects of compaction and gravity (Dong and Pan [2]). Stresses due to construction operations and traffic are anisotropic and new particle contacts are formed due to breakage and slippage of particles, which induces further anisotropy (Dong and Pan, 1999). To more accurately investigate the effect of stress-dependency of granular materials on pavement response and surface deflection predictions, researchers developed a method to fully characterize the stress-sensitive and cross-anisotropic properties of unbound aggregate bases, which are resilient moduli in the vertical and radial directions, Ey and Ex; shear modulus in vertical direction, Gxy; Poisson's ratio for strain in the vertical direction due to a horizontal direct stress, $v_{x y}$; and Poisson's ratio for strain in any horizontal direction due to a horizontal direct stress, $v_{x x}$ (Tutumluer et al. [9], Kim et al. [4]).

As expressed in Eqs. (1) through (3), the modulus of the unbound aggregate base was modeled using an Uzan type stress-dependent model with a cross-anisotropic approach based on the recent studies that emphasized the importance of accounting not only for stress dependency but also the anisotropy in order to properly model the unbound aggregate modulus properties and the stress state distributions in the layer (Tutumluer et al. [9], Kim et al. [4]).

$$
\begin{gathered}
E_{y}=k_{1}\left(\frac{I}{P_{a}}\right)^{k_{2}}\left(\frac{\tau_{o c t}}{P_{a}}\right)^{k_{3}} \\
n=E_{x} / E_{y} \\
m=G_{x y} / E_{y}
\end{gathered}
$$


In Eqs. (2.1), (2.2), and (2.3), $\mathrm{E}_{y}$ is the vertical modulus, $\mathrm{E}_{x}$ is the horizontal modulus, $\mathrm{G}_{x y}$ is the shear modulus, $\mathrm{I}$ is the first stress invariant (bulk stress), $\tau_{o c t}$ is the octahedral shear stress, $\mathrm{P}_{a}$ is the atmospheric pressure, and $\mathrm{k}_{i}$ are material model parameters obtained from regression analyses of the laboratory modulus test data.

To consider the anisotropic behavior of HMA layer, the horizontal and shear moduli ratio was approximated and used as an input for the FEM analysis.

\section{FIELD RESPONSE TEST}

The KHCTR has been regarded as the most realistic research tool to evaluate the performance of pavements influenced by many complex variables such as construction, traffic, climatic, materials, etc. Test road in Korea was first constructed in December 2002 and opened to traffic in March 2004. Road research institute at the Korea Highway Corporation (KHC) played a leading role in the construction and operation of this test road, and conducted a wide range of field tests to better characterize the response and performance of highway pavements (Seo [7] and [8]). The KHCTR is located between the Yeo-ju junction on Interstate 50 and the Gam-gok interchange on Interstate 45, and it goes almost parallel to the Interstate 45 . This two-lane, $7.7 \mathrm{~km}$-long highway was composed of 25 concrete and 33 asphalt sections as illustrated in Fig. 1.

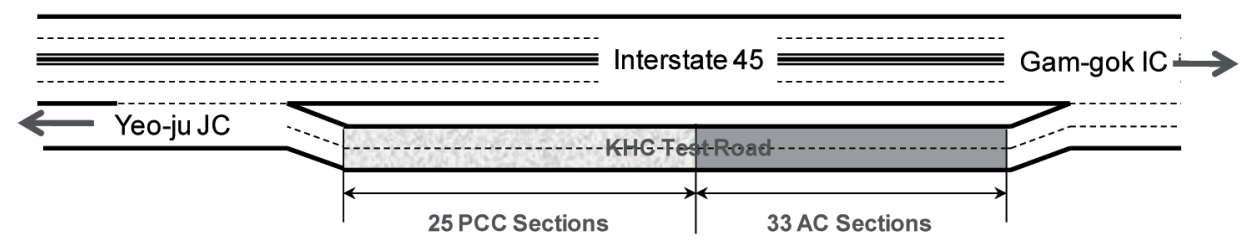

Fig. 1. Plan view of KHCTR.

With projected AADT (Average Annual Daily Traffic) of 57,520 in year 2011 and a load distribution factor of 0.8 , the traffic volume for a 10-year design life was estimated to be 44.7 million $80-\mathrm{kN}$ ESALs (Equivalent Single Axle Loads) for all pavement sections. The AASHTO interim design guide was adopted for the structural design of both pavement types. Detailed information on design and construction of the KHCTR can be found elsewhere (KHC 2002).

Approximately 1,900 sensors were installed at KHCTR to obtain stress and strain responses and to monitor moisture and temperature variations at different locations of sections during construction. Most of asphalt sections were instrumented with 636 sensors that include strain gauges, soil pressure cells and thermal couples. Fig. 2 illustrates a sensor layout for one of asphalt sections, A5, where strain gauges were placed in longitudinal and transverse directions to quantify the anisotropic levels in HMA layers In Fig. 2, ASTM 19 is the 19-mm dense graded HMA used for surface layer, BB5 is the 25-mm dense graded HMA used for intermediate layer, and BB3 is the 
25-mm dense graded HMA used for base layer. Thermocouples were also embedded from the surface to the bottom of asphalt layer and those measurements were considered as inputs for the FEM described in subsequent sections.

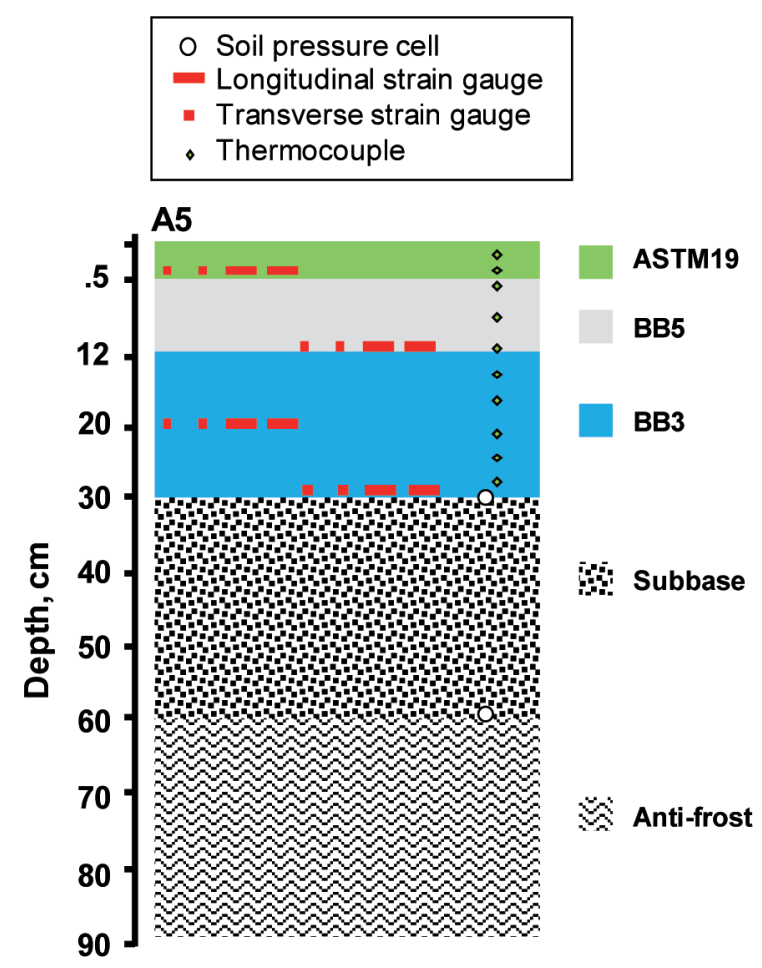

Fig. 2. Cross-section and sensor layout of A5 at KHCTR.

A series of moving load tests was performed at A5 with a dump truck. A three-axle dump truck (single tire front and dual tire rear tandem) with a 12R22.5 type radial tire was utilized as a load source all along. This test vehicle was operated by the same highly trained driver to minimize natural sway in a moving vehicle. The planar configuration of tire and axle is seen in Fig. 3. During testing, air pressures for tires of each axle were maintained at levels: $1076 \mathrm{kPa}$ (1st axle), $828 \mathrm{kpa}$ (2nd axle), and $1076 \mathrm{kpa}$ (3rd axle). These pressure levels have been determined by averaging field survey data collected at countrywide weighing stations in Korea.

The test results conducted was selected for the implementation of FEM developed in this study. The full-scale pavement test results were shown in Table 1. First and second values in the table were the minimum and maximum from the experiments, respectively. 


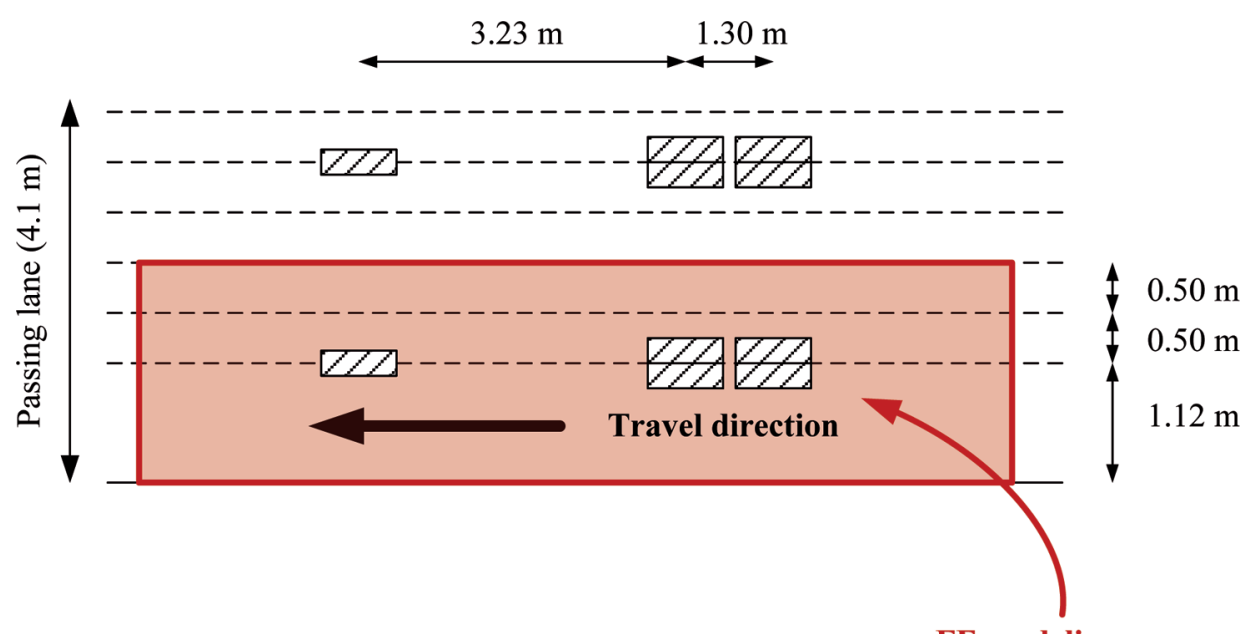

FE modeling area

Fig. 3. Plan view of the passing lane at A5 asphalt section.

Table 1

Performance Response Summary of Pavement Test Sections.

\begin{tabular}{|c|c|c|c|c|}
\hline \multicolumn{2}{|c|}{ Top Anti-frost } & \multicolumn{2}{c|}{ Top Subbase } & Bottom AC \\
\hline $\begin{array}{c}\text { Vertical Stress } \\
(\mathrm{kPa})\end{array}$ & $\begin{array}{c}\text { Vertical Strain } \\
\left(10^{-6}\right)\end{array}$ & $\begin{array}{c}\text { Vertical Stress } \\
(\mathrm{kPa})\end{array}$ & $\begin{array}{c}\text { Vertical Strain } \\
\left(10^{-6}\right)\end{array}$ & $\begin{array}{c}\text { Horizontal Strain } \\
\left(10^{-6}\right)\end{array}$ \\
\hline $19.3-$ & N/A & $36.4-$ & N/A & $30.6-$ \\
24.8 & 81.9 & & 56.5 \\
\hline
\end{tabular}

\section{Analysis of the Results}

A pavement comprised of a 120-mm HMA layer, a 180-mm unstabilized base course, a 300-mm thick stress softening subbase layer, and a 300-mm thick anti-frost layer was used for the KHCTR section model. As shown in Figs. 1 and 2, a three-axle truck was passing through the lane and the half of the area was adapted to the FE simulation. The red area shows the FEM model part and a 26,416-element and 17,866-node ABAQUS FEM model was generated. Fig. 4 showed the three dimensional finite element mesh model representing loading area and the red area on the top represented the loading location. The perimeter boundary conditions were assumed as simply supported. Loads of $27.2 \mathrm{kN}, 21.5 \mathrm{kN}$, and $21.9 \mathrm{kN}$ were applied for front, middle, and back tire areas respectively. A fixed boundary condition was also assumed at the bottom of the section. A regression equation that fits the temperature profile data was developed as shown in Eq. (4.1) and implemented into the FEM model.

$$
\text { Temperature }=20.411(\text { depth })^{-0.175}
$$




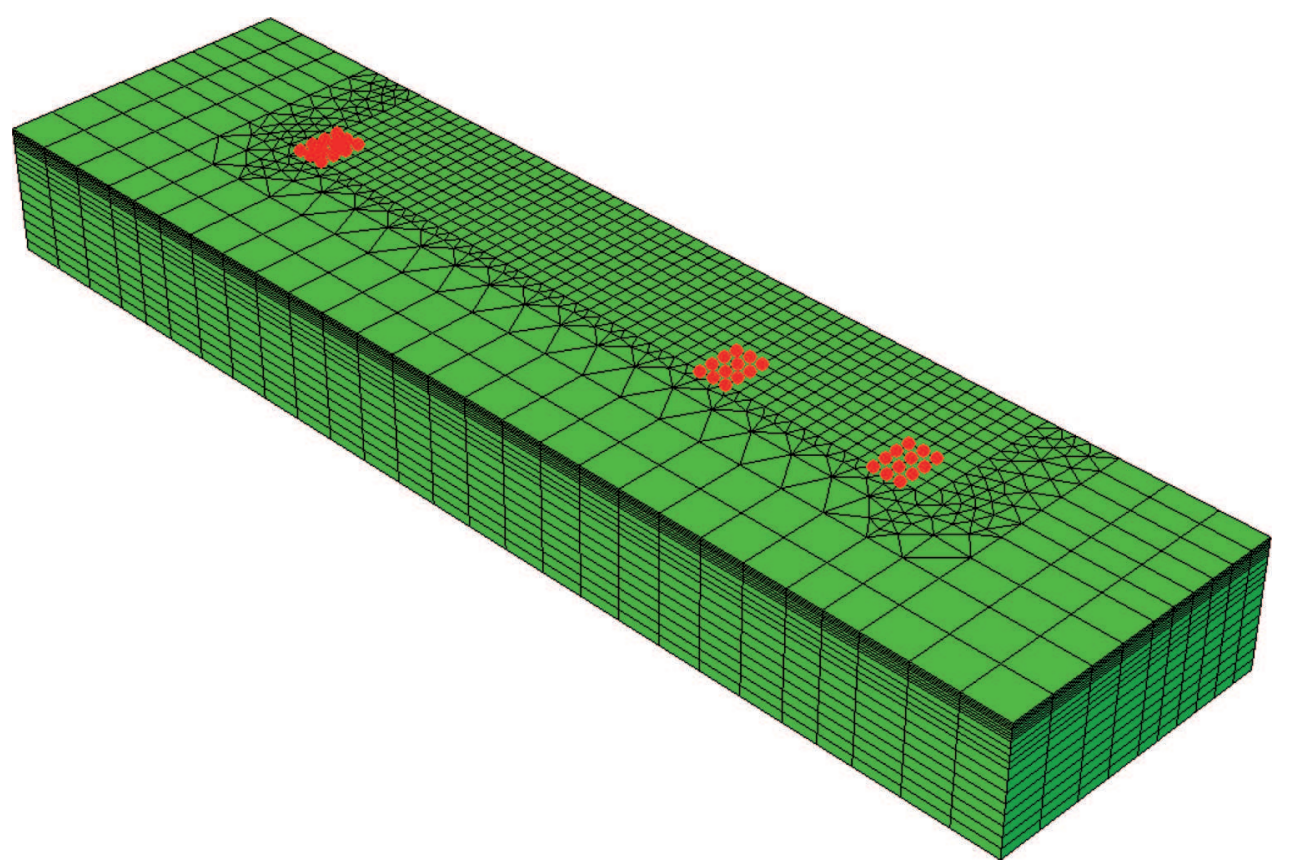

Fig. 4. Finite Element (FE) model with mesh and loading area.

In order to develop values for vertical and horizontal resilient modulus ratios, twelve sensitive analyses were performed with different level of anisotropy. All materials were assumed as anisotropic material except anti-frost layer and Table 2 shows the material properties used in the FEM models.

Table 3 shows the comparisons between the measured data collected from the KHCTR and FEM results for the simulations. Based on comparisons, the higher value of the vertical strain at the top of anti-frost layer was obtained when the unbound aggregate base and HMA layer were modeled as 15\% level of anisotropy and $70 \%$ level of anisotropy. Similarly, the tensile strains at the bottom of HMA decreased considerably when the analysis was transitioned from the linear isotropic case without considering the temperature profile variation to the anisotropic analyses with the consideration of temperature profile variation throughout the HMA layer. These are the critical pavement responses that are directly related to rutting and asphalt fatigue cracking that significantly contribute to the overall pavement performance and overlay design. 
Table 2

Anisotropic Material Properties.

\begin{tabular}{|c|c|c|c|c|c|c|c|}
\hline $\begin{array}{l}\text { Simulation } \\
\text { Number }\end{array}$ & Layer Type & $\begin{array}{c}\text { Thickness } \\
\text { (m) }\end{array}$ & $\begin{array}{c}\text { Vertical } \\
\text { Resilient } \\
\text { Modulus } \\
\text { (MPa) }\end{array}$ & $\begin{array}{c}\text { Vertical } \\
\text { Poisson's } \\
\text { Ratio }\end{array}$ & $\begin{array}{c}\text { Horizontal } \\
\text { Resilient } \\
\text { Modulus } \\
\text { (MPa) }\end{array}$ & $\begin{array}{c}\text { Horizontal } \\
\text { Poisson's } \\
\text { Ratio }\end{array}$ & $\begin{array}{l}\text { Shear } \\
\text { Stress } \\
\text { (MPa) }\end{array}$ \\
\hline \multirow{4}{*}{$\begin{array}{l}\text { HMA: } 70 \% \\
\text { Base: } 15 \%\end{array}$} & HMA & 0.12 & 2760 & 0.35 & 1930 & 0.245 & 1930 \\
\hline & Base & 0.18 & 517 & 0.35 & 78 & 0.05 & 78 \\
\hline & Subbase & 0.30 & 241 & 0.35 & 36 & 0.05 & 36 \\
\hline & Anti-frost & 0.30 & 69 & 0.40 & - & - & - \\
\hline \multirow{4}{*}{$\begin{array}{l}\text { HMA: } 70 \% \\
\text { Base: } 30 \%\end{array}$} & HMA & 0.12 & 2760 & 0.35 & 1930 & 0.245 & 1930 \\
\hline & Base & 0.18 & 517 & 0.35 & 155 & 0.11 & 155 \\
\hline & Subbase & 0.30 & 241 & 0.35 & 72 & 0.11 & 72 \\
\hline & Anti-frost & 0.30 & 69 & 0.40 & - & - & - \\
\hline \multirow{4}{*}{$\begin{array}{c}\text { HMA: } 70 \% \\
\text { Base: } 50 \%\end{array}$} & HMA & 0.12 & 2760 & 0.35 & 1930 & 0.245 & 1930 \\
\hline & Base & 0.18 & 517 & 0.35 & 259 & 0.18 & 259 \\
\hline & Subbase & 0.30 & 241 & 0.35 & 121 & 0.18 & 121 \\
\hline & Anti-frost & 0.30 & 69 & 0.40 & - & - & - \\
\hline \multirow{4}{*}{$\begin{array}{c}\text { HMA: } 80 \% \\
\text { Base: } 15 \%\end{array}$} & HMA & 0.12 & 2760 & 0.35 & 2210 & 0.28 & 2210 \\
\hline & Base & 0.18 & 517 & 0.35 & 78 & 0.05 & 78 \\
\hline & Subbase & 0.30 & 241 & 0.35 & 36 & 0.05 & 36 \\
\hline & Anti-frost & 0.30 & 69 & 0.40 & - & - & - \\
\hline \multirow{4}{*}{$\begin{array}{l}\text { HMA: } 80 \% \\
\text { Base: } 30 \%\end{array}$} & HMA & 0.12 & 760 & 0.35 & 2210 & 0.28 & 2210 \\
\hline & Base & 0.18 & 517 & 0.35 & 155 & 0.11 & 155 \\
\hline & Subbase & 0.30 & 241 & 0.35 & 72 & 0.11 & 72 \\
\hline & Anti-frost & 0.30 & 69 & 0.40 & - & - & - \\
\hline \multirow{4}{*}{$\begin{array}{l}\text { HMA: } 80 \% \\
\text { Base: } 50 \%\end{array}$} & HMA & 0.12 & 2760 & 0.35 & 2210 & 0.28 & 2210 \\
\hline & Base & 0.18 & 517 & 0.35 & 259 & 0.18 & 259 \\
\hline & Subbase & 0.30 & 241 & 0.35 & 121 & 0.18 & 121 \\
\hline & Anti-frost & 0.30 & 69 & 0.40 & - & - & - \\
\hline \multirow{4}{*}{$\begin{array}{c}\text { HMA: } 90 \% \\
\text { Base: } 15 \%\end{array}$} & HMA & 0.12 & 2760 & 0.35 & 2480 & 0.32 & 2480 \\
\hline & Base & 0.18 & 517 & 0.35 & 78 & 0.05 & 78 \\
\hline & Subbase & 0.30 & 241 & 0.35 & 36 & 0.05 & 36 \\
\hline & Anti-frost & 0.30 & 69 & 0.40 & - & - & - \\
\hline \multirow{4}{*}{$\begin{array}{c}\text { HMA: } 90 \% \\
\text { Base: } 30 \%\end{array}$} & HMA & 0.12 & 2760 & 0.35 & 2480 & 0.32 & 2480 \\
\hline & Base & 0.18 & 517 & 0.35 & 155 & 0.11 & 155 \\
\hline & Subbase & 0.30 & 241 & 0.35 & 72 & 0.11 & 72 \\
\hline & Anti-frost & 0.30 & 69 & 0.40 & - & - & - \\
\hline \multirow{5}{*}{$\begin{array}{c}\text { HMA: } 80 \% \\
\text { Base: } 50 \%\end{array}$} & HMA & 0.12 & 2760 & 0.35 & 2480 & 0.32 & 2480 \\
\hline & Base & 0.18 & 517 & 0.35 & 259 & 0.18 & \\
\hline & Subbase & 0.30 & 241 & 0.35 & 121 & 0.18 & 121 \\
\hline & Anti-frost & 0.30 & 69 & 0.40 & - & - & - \\
\hline & Anti-frost & 0.30 & 69 & 0.40 & - & - & - \\
\hline
\end{tabular}




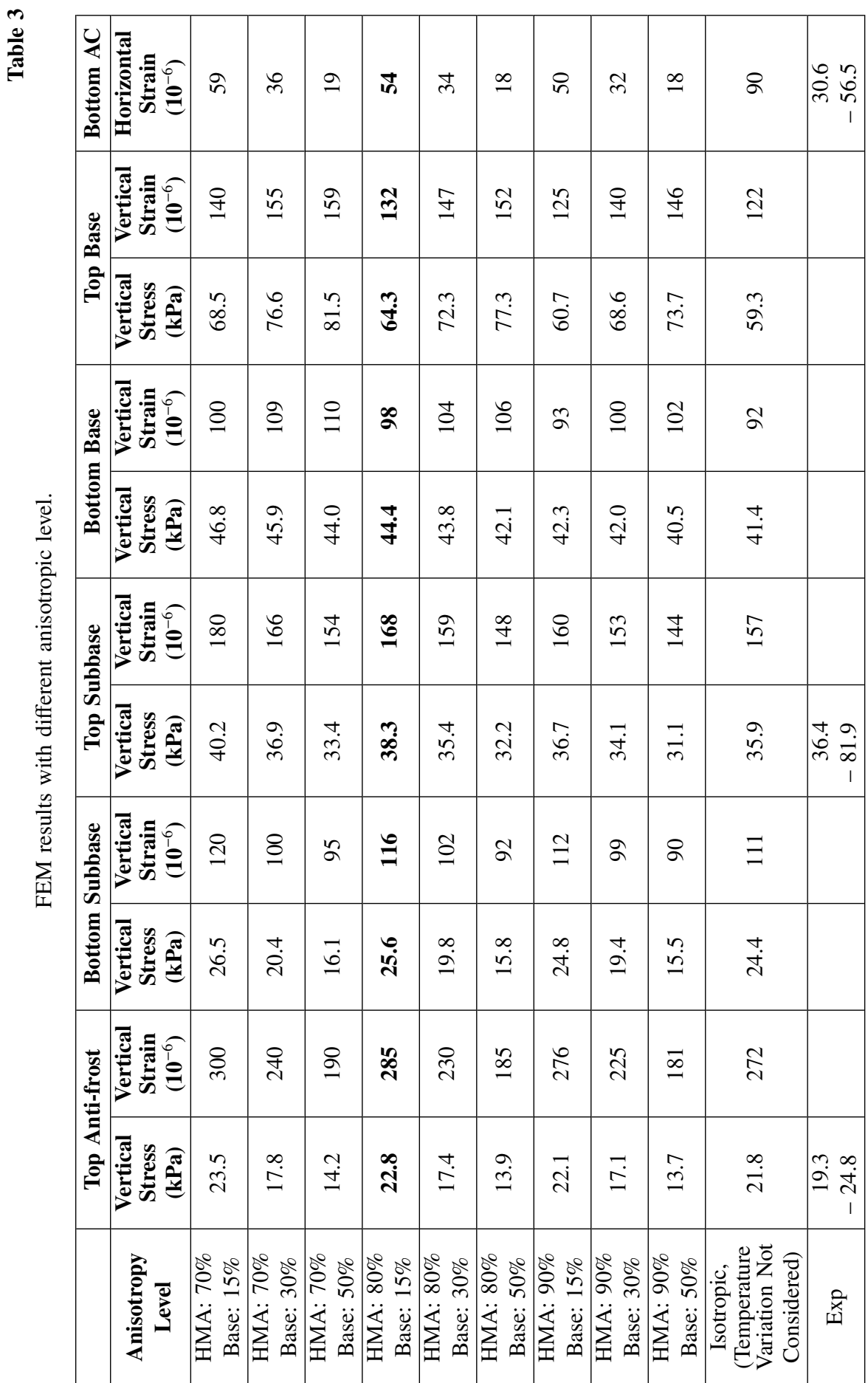


Table 3 also compares the measured pavement responses with the three dimensional FEM predictions from the different analyses. In general, the predicted pavement responses from FEM analysis with the anisotropic model for HMA and aggregate base are in reasonably good agreement with the measured pavement responses from KHCRT when the HMA layer and Base layer is considered as $80 \%$ and $15 \%$ level of anisotropy, separately, with the temperature profile consideration throughout the pavement. This indirectly shows that anisotropic modeling and temperature variation consideration of HMA and base layers provide a much more realistic approximation of the measured responses. With better and more accurate predictions of these responses, a more structurally adequate pavement can be designed.

\section{Conclusion}

The synergistic effect of anisotropic behavior of HMA and base layers considering the temperature variation throughout the HMA layer was investigated by performing a three dimensional finite element analyses. The results from the ABAQUS finite element models clearly showed that anisotropic model of both the asphalt and aggregate base layers gave the most realistic predictions when compared to measured values for pavement responses. Substantially higher critical pavement responses were predicted with the increased anisotropic level of HMA and base layer. Horizontal strain is a critical pavement response, which is directly related to fatigue performance, and the level of anisotropy of HMA and aggregate base impacts the stress and strain distributions. With better and more accurate predictions of these responses, a structurally more adequate pavement can be designed.

\section{REFERENCES}

1. B. K. Diefenderfer, I. L. Al-QAdi, S. D. Diefenderfer, Model to Predict Pavement Temperature Profile: Development and Validation, Journal of Transportation Engineering, 132, 2, 162-167, 2006.

2. J.J. Dong, Y.W. Pan, Micromechanics Model for Elastic Stiffness of Non-Spherical Granular Assembly International J. Numer. Anal. Meth. Geomech., 23, 1075-1100, 1999.

3. S.H. Кim, D. N. Little, E. Tutumluer, Validated Model for Predicting Field Performance of Aggregate Base Courses, Transportation Research Record 1873, paper no. 03-3404, 2003.

4. S. H. Kim, D. N. Little, E. Masad, Simple Methods to Estimate Inherent and Stress-Induced Anisotropic Level of Aggregate Base Transportation Research Record 1913, TRB, National Research Council, Washington D.C, 2431, 2005.

5. S. H. Kim, D. N. Little, E. Tutumluer, Effect of Gradation on Nonlinear Stress-Dependent Behavior of a Sandy Flexible Pavement Subgrade, Journal of Transportation Engineering, 133, 10, 582-589, 2007.

6. Korea Highway Corporation, A Study on the Construction and Management of Korea Highway Test Road, Final Report, 2002.

7. Y. Seo, Distress Evolution in Highway Flexible Pavements: A 5-Year Study at the KHC Test Road, ASTM, Journal of Testing and Evaluation, 38, 1, 32-41, 2010. 
8. Y. Seo, A Full Scale In Situ Evaluation of Strain Characteristics at Highway Flexible Pavement Sections, ASTM Journal of Testing and Evaluation, 38, 4, 390-399, 2010.

9. E. Tutumluer, D.N. Little, S. H. Kim, Validated Model for Predicting Field Performance of Aggregate Base Courses. Transportation Research Record 1837, TRB, National Research Council, Washington D.C., pp. 41-49, 2003.

Remarks on the paper should be sent to the Editorial Office no later than March 31, 2012
Received September 12, 2011 revised version December 14, 2011 